Jurnal Agroteknologi, Vol. 9 No. 1, Agustus 2018 : halawal - halakhir(diisi oleh editor)

\title{
PERTUMBUHAN PADI GOGO PADA MEDIUM ULTISOL DENGAN APLIKASI BIOCHAR DAN ASAP CAIR
}

\author{
Application of Biochar dan Liquid Smoke to the Growth of Upland Rice (Oryza sativa. L) on Ultisol \\ Medium \\ JOHN IVAN NDRURU ${ }^{1}$, NELVIA $^{2}$ DAN ADIWIRMAN ${ }^{2}$ \\ ${ }^{1}$ Mahasiswa Program Studi Magister IImu Pertanian Pascasarjana Universitas Riau \\ ${ }^{2}$ Staff Pengajar Program Studi Magister Fakultas Pertanian Universitas Riau Kampus Bina Widya \\ Km. 12.5 Simpang Baru Pekanbaru (28293) \\ Email : ivanndruru@gmail.com
}

\begin{abstract}
The research aims to study effect of interaction of biochar and liquid smoke, application of biochar and liquid smoke to the growth of upland rice on Ultisol medium. The research was conducted at the green house Faculty of Agriculture, Riau University on January to June 2017. The form of this research is experimental factorial completely randomized design consist of two factors. The first factors is biochar consists of four levels (0/without biochar, 10 ton ha-1 rice husk, 10 ton ha-1 coconut shell, and composite of rice husk 5 ton ha-1 and coconut shell 5 ton ha- 1). The second factors is liquid smoke witch consisted of 3 levels (0/without liquid smoke, 0.5\% rice husk, and 0.5\% coconut shell) each combination was repeated three times. The results showed that the application of biochar (rice husk, coconut shell and composite of rice husk and coconut shell) dose 10 ton ha-1 increase plant height, maximum and productive number of tillers, dry weight of straw and decrease of flowering time. The application of liquid smoke $0.5 \%$ of rice husk and coconut shell increase plant height, dry weight of straw and decrease of flowering time. The application of composite of biochar (rice husk, coconut shell and composite of rice husk and coconut shell) dose 10 ton ha-1 and liquid smoke $0.5 \%$ (rice husk and coconut shell) increase plant height, productive number of tillers and dry weight of straw and decrease of flowering time compared without application.
\end{abstract}

Keywords : Biochar, liquid smoke, upland rice.

\section{PENDAHULUAN}

Padi (Oriza sativa L.) merupakan tanaman penghasil makanan pokok bagi sebagian besar penduduk di Indonesia di samping jagung dan umbi-umbian. Padi dapat ditanam di lahan kering maupun lahan basah (sawah). Padi gogo merupakan tanaman yang ditanam pada lahan kering yang datar maupun berlereng dimana pertumbuhan dan produksinya sangat tergantung pada curah hujan. (Departemen Pertanian, 2008).

Produksi padi gogo pada tingkat petani masih rendah, karena lahan kering yang ditanami tergolong marginal, salah satunya lahan Ultisol. Lahan Ultisol bercirikan tanah mineral masam tersebar luas di Indonesia mencapai 45.8 juta hektar (Prasetyo dan Suriadikarta, 2006). Ultisol merupakan tanah mineral masam yang potensial yang memiliki luas mencapai 45,8 juta hektar atau sekitar $25 \%$ dari total luas daratan Indonesia.

Pada umumnya Ultisol mempunyai produktifitas yang rendah karena tingkat kesuburannya yang juga tergolong rendah. Rendahnya produktifitas Ultisol menurut
Subagyo et al. (2004) dikarenakan umumnya tanah ini mempunyai horizon A yang tipis, dengan kandungan bahan organik dan hara yang rendah. Sifat kimia Ultisol umumnya mempunyai nilai kejenuhan basa $<35 \%$, reaksi tanah yang masam $(\mathrm{pH} 3.10-5)$ dan kelarutan $P$ yang rendah yang disebabkan oleh pengaruh aluminium (Al) dalam larutan yang cukup tinggi, KTK yang rendah berkisar 1.20$12.50 \mathrm{cmol} \mathrm{kg}-1$ akibat dominasi mineral kaolinit (Prasetyo dan Suriadikarta, 2006). Oleh karena itu maka diperlukan usaha untuk memperbaiki kesuburan tanahnya agar dapat menjadi lahan yang potensial untuk pengembangan pertanian khususnya padi gogo.

Salah satu upaya yang dapat dilakukan untuk memperbaiki sifat tanah Ultisol yaitu dengan memanfaatkan bahan organik sisa panen atau limbah pertanian seperti tempurung kelapa dan sekam padi dalam bentuk biochar. Biochar merupakan arang hayati yang berasal dari bahan-bahan organik sisa-sisa hasil pertanian dan dihasilkan melalui proses pembakaran tidak sempurna (pirolisis). Biochar lebih efektif menahan unsur hara 
untuk ketersediaannya bagi tanaman dibandingkan bahan organik lain. Chan et al. (2007) Hal ini disebabkan karena biochar memiliki sifat retensi dan persistensi atau kestabilan yang sangat tinggi terhadap unsurunsur hara di dalam tanah. Bahkan menurut Lehman (2007) pembenaman biochar dalam tanah dapat menyimpan karbon scara stabil hingga ribuan tahun. Penambahan biochar dalam tanah berpengaruh positif terhadap perbaikan kualitas tanah seperti stabilitas agregat tanah, KTK tanah, kandungan Corganik tanah, retensi air dan hara (Glaser et al, 2002).

Hasil analisis komponen biochar asal cangkang kelapa sawit yang dilakukan oleh Endriani (2013), melaporkan bahwa biochar mengandung $48.56 \%$ C-organik dan $\mathrm{C} / \mathrm{N}$ 35.45 , kadar $\mathrm{P} 0.94 \%$, kadar $\mathrm{K} 0.28 \%$ dan $\mathrm{pH}$ 6.71 Ditambahkannya bahwa dengan pemberian biochar cangkang kelapa sawit ke dalam tanah dapat meningkatkan $\mathrm{pH}$ tanah sebesar 5.30 yang semula memiliki pH 4.36. Hasil penelitian Gani (2010) menyatakan pemberian biochar 4-8 ton ha-1 dapat meningkatkan produktivitas padi secara nyata antara $20-220 \%$. Begitu juga hasil penelitian Chan et al. (2007) melaporkan kombinasi biochar dan pupuk $\mathrm{N}$ dapat meningkatkan hasil panen sawi hingga $95 \%$.

Proses produksi biochar (pirolisis), akan menghasilkan produk sampingan dalam bentuk asap yang apabila dikondensasi akan membentuk tetesan- tetesan air atau yang disebut dengan asap cair (liquid smoke). Asap cair merupakan hasil kondensasi daari pirolisis kayu yang mengandung sejumlah besar senyawa yang terbentuk akibat proses pirolisis konstituen kayu seperti sellulosa, hemisellulosa dan lignin (Darmaji, 1996). Hasil penelitian pada rumput raja (Pennisetum purpureophoides) yang dilakukan Muhakka et al. (2013) menyatakan bahwa pemberian asap cair dapat menghasilkan tanaman tertinggi yakni $382.50 \mathrm{~cm}$. Menurut Yatagai (2002), komponen kimia asap cair seperti asam asetat berfungsi untuk mempercepat pertumbuhan tanaman, pencegah penyakit tanaman. Metanol berfungsi untuk mempercepat pertumbuhan tanaman, sedangkan phenol dan turunannya berfungsi untuk mencegah serangan hama dan penyakit tanaman. Tsuzuki et al (1989) melaporkan bahwa pemberian pyroligneous acid atau asap cair dapat mempercepat pertumbuhan akar tanaman serta berat kering akar dan tajuk tanaman.

Penelitian ini bertujuan untuk mempelajari pengaruh biochar, asap cair dan interaksi keduanya pada pertumbuhan padi gogo pada medium Ultisol.

\section{BAHAN DAN METODE}

Penelitian ini dilakukan di Rumah Kaca dan Laboratorium Tanah Fakultas Pertanian Universitas Riau pada bulan Januari - Juni 2017. Adapun bahan yang digunakan yaitu bahan tanah Ultisol yang diambil di Desa Batu Belah, Kampar, Riau, biochar dan asap cair dari sekam padi dan tempurung kelapa, $\mathrm{NaOH}$ $1 \%$, benih padi Situpatenggang, pupuk dasar (urea, TSP dan $\mathrm{KCl}$ ) dan pestisida Curacron untuk mengendalikan hama dan Rhidomil untuk penyakit.

Penelitian dalam bentuk factorial $4 \times 3$ menggunakan rancangan acak lengkap (RAL). Faktor pertama yaitu biochar dosis 10 ton ha-1 terdiri dari 4 taraf yaitu tanpa biochar/kontrol, biochar sekam padi (SP), biochar tempurung kelapa TK dan campuran biochar (SP 5 ton ha$1+$ TK 5 ton ha-1). Faktor kedua yaitu asap cair konsentrasi $0.5 \%$ terdiri dari 3 taraf yakni tanpa asap cair (kontrol), asap cair sekam padi (SP) dan asap cair tempurung kelapa (TK) dan masing-masing kombinasi diulang 3 kali.

Tanah yang akan digunakan diambil secara komposit pada kedalaman $0-20 \mathrm{~cm}$ (lapisan olah) dan dikeringanginkan kemudian diayak dengan ayakan $2 \mathrm{~mm}$. Tanah yang telah diayak kemudian dimasukkan ke dalam pot sebanyak $10 \mathrm{~kg} /$ pot. Bahan baku sekam padi dan tempurung kelapa yang telah dikeringanginkan, kemudian dipirolisis pada alat pirolisator untuk mendapatkan biochar dan asap cair. Biochar yang didapatkan lalu dibiarkan selama satu hari kemudian ditumbuk halus dengan ayakan $2 \mathrm{~mm}$, setelah itu biochar masing-masing ditimbang sebanyak 50 g pot-1 (10 ton ha-1) dan $25 \mathrm{~g}$ (5 ton ha-1). Setelah itu biochar dicampurkan dengan $\mathrm{NaOH} 1 \%$ dan diinkubasi selama 1 hari dengan tujuan untuk menurunkan sifat kristalinitas dan meningkatkan daya adsorpsi biochar. Setelah diinkubasi biochar kemudian dicampurkan ke dalam tanah secara merata beserta pemberian pupuk urea, TSP dan $\mathrm{KCl}$. Tanah yang telah diperlakukan dibiarkan selama seminggu kemudian dilakukan penanaman padi varietas Situpatenggang dengan cara ditugal dengan jumlah benih 5 butir pot-1. Asap cair diberikan pada umur 45 hari setelah tanaman dengan metoda penyemprotan 1 kali seminggu pada seluruh bagian tanaman hingga seminggu sebelum panen. 
Adapun parameter yang diamati yakni, tinggi tanaman, jumlah anakan maksimum, jumlah anakan produktif, umur keluar malai, bobot kering jerami, dan indeks panen. Data hasil pengamatan yang diperoleh dianalisis secara statistik dengan analisis ragam dan dilanjutkan dengan uji BNJ pada taraf $5 \%$.

HASIL DAN PEMBAHASAN

\section{Tinggi Tanaman}

Tabel 1. Tinggi Tanaman Padi $(\mathrm{cm})$ yang diberi Biochar dan Asap Cair dari Sekam Padi dan Tempurung Kelapa.

\begin{tabular}{lccc}
\hline $\begin{array}{c}\text { Jenis Biochar } \\
\text { (ton ha }{ }^{-1} \text { ) }\end{array}$ & Tanpa Asap Cair & $\begin{array}{c}\text { Asap Cair (\%) } \\
\text { SP }(0,5)\end{array}$ & TK $(0,5)$ \\
\hline Tanpa Biochar & $------------------106.17 \mathrm{e}$ & $106.73 \mathrm{de}$ \\
SP $(10)$ & $104.37 \mathrm{e}$ & $118.53 \mathrm{ab}$ & $109.90 \mathrm{~d}$ \\
TK (10) & $107.43 \mathrm{de}$ & $113.77 \mathrm{c}$ & $115.07 \mathrm{bc}$ \\
SP (5) + TK (5) & $107.70 \mathrm{de}$ & $119.67 \mathrm{a}$ & $115.63 \mathrm{bc}$ \\
\hline
\end{tabular}

Keterangan : Angka - angka yang diikuti oleh huruf kecil yang sama menunjukkan berbeda tidak nyata menurut uji lanjut $\mathrm{BN} J$ taraf $5 \% . S P=$ Sekam Padi dan TK = Tempurung Kelapa.

Peningkatan tinggi tanaman pada pemberian biochar disebabkan karena biochar mengandung unsur $\mathrm{N}, \mathrm{P}$ dan $\mathrm{K}$ serta kation basa lainnya yang dapat diberika ke dalam tanah. Selain itu sifat biochar SP dan TK yang lebih porous dan memiliki KTK yang tinggi masing-masing yakni $(21.86$ dan $53.05 \mathrm{cmol}$ $\mathrm{kg}$-1) mampu meretensi hara dan air sehingga ketersediaanya bagi tanaman mencukupi terutama dalam proses fisiologi dan metabolisme tanaman yang akhirnya akan meningkatkan pertumbuhan tinggi tanaman. Hasil penelitian Saputra et al. (2016) menyatakan bahwa pemberian biochar sekam padi dan pupuk anorganik memiliki rata-rata nilai tinggi tanaman yang paling tinggi diantara perlakuan lainnya.

Demikian halnya pada pemberian asap cair SP dan TK (Tabel 1) mampu meningkatkan tinggi tanaman masing- masing sebesar 10.16 dan $7.46 \mathrm{~cm}$. Hal ini disebabkan oleh kandungan senyawa organik yang terdapat dalam asap cair. Van staden et al. (2006) menyatakan bahwa asap cair lebih berperan dalam merangsang pertumbuhan tanaman (plant growth promotor). Yatagai (2002) menyatakan bahwa kandungan asam asetat dan methanol pada asap cair dapat merespos atau merangsang pertumbuhan tanaman. Hasil penelitian pada rumput raja
(Pennisetum purpureophoides) yang dilakukan Muhakka et al. (2013) menyatakan bahwa pemberian asap cair dapat menghasilkan tanaman tertinggi yakni $382.50 \mathrm{~cm}$ dibandingkan tanpa asap cair.

Kombinasi antara biochar campuran $(\mathrm{SP}+\mathrm{TK})$ diikuti pemberian asap cair (SP) mampu meningkatkan tinggi tanaman disebabkan oleh ketersediaan hara di dalam tanah tercukupi dengan pemberian biochar dan melalui penyemprotan asap cair dapat merangsang pertumbuhan tanaman sehingga menghasilkan tinggi tanaman tertinggi $(119.67 \mathrm{~cm})$. Tinggi tanaman yang dihasilkan oleh perlakuan ini lebih tinggi bila dibandingkan dengan deskripsi tanaman yang memiliki tinggi $(100-110 \mathrm{~cm})$.

\section{Jumlah Anakan Maksimum}

Tabel 2 menunjukkan bahwa jumlah anakan maksimum cenderung meningkat pada pemberian biochar SP, begitu juga pada pemberian asap cair SP dan TK, bahkan pada pemberian biochar TK dan campuran (SP+TK) terjadi peningkatan secara nyata berturutturut sebesar 11 dan 13.67 batang, sedangkan interaksi antara biochar (TK) dan asap cair (TK) jumlah anakannya lebih banyak dibandingkan tanpa perlakuan (kontrol).

Tabel 2. Jumlah Anakan Maksimum (batang) Tanaman Padi yang diberi Biochar dan Asap Cair dari Sekam Padi dan Tempurung Kelapa.

\begin{tabular}{ccccc}
\hline $\begin{array}{c}\text { Jenis Biochar } \\
\text { (ton ha } \text { h }^{-1} \text { ) }\end{array}$ & Tanpa Asap Cair & $\begin{array}{c}\text { Asap Cair (\%) } \\
\text { SP }(0,5)\end{array}$ & TK $(0,5)$ & Rata-Rata \\
\hline \multirow{2}{*}{ Tanpa Biochar } & 29.33 & 30.33 & 29.67 & 29.78 \\
SP (10) & 35.33 & 36.33 & 39.00 & 36.89 \\
\hline
\end{tabular}




\begin{tabular}{lllll}
\hline TK (10) & 36.00 & 37.67 & 47.33 & 40.33 \\
SP (5) + TK (5) & 43.67 & 44.00 & 41.33 & 43.00 \\
\hline Rata-Rata & 36.08 & 37.08 & 39.33 & \\
\hline
\end{tabular}

Keterangan : Angka - angka yang diikuti oleh huruf kecil yang sama menunjukkan berbeda tidak nyata menurut uji lanjut BNJ taraf 5\%. SP = Sekam Padi dan TK = Tempurung Kelapa.

Tabel 2 menunjukkan peningkatan jumlah anakan maksimum oleh pemberian biochar disebabkan karena biochar telah diaktifkan dengan $\mathrm{NaOH} 1 \%$. Pengaktifan ini menyebabkan $\mathrm{pH}$ biochar tergolong tinggi (9.63) serta kapasitas tukar kationnya yang tinggi (21-53 cmol kg-1). Menurut Endriani (2013) pemberian biochar asal cangkakng sawit dapat meningkatkan $\mathrm{pH}$ tanah sebesar 5.30. Jamilah (2014) melaporkan bahwa interaksi antara biochar dan pupuk urea dapat meningkatkan jumlah anakan maksimum pada umur 30 hari setelah tanam. Menurut Liang et al. (2006) penggunaan biochar dapat meningkatkan $\mathrm{pH}$ tanah dan meningkatkan KTK tanah. Kemampuan tanah dalam mempertukarkan kation yang tinggi akan menjerap kation- kation basa seperti $\mathrm{Ca}, \mathrm{Mg}, \mathrm{K}$ dan $\mathrm{Na}$ serta unsur nitrogen dan fosfat pada koloid tanah sehingga ketersediaan hara bagi tanaman mencukupi dalam menjalankan aktifitas metabolisme dan fisiologinya. Marschener, (1995) menyatakan bahwa unsur hara yang tersedia cukup dalam tanah terutama $\mathrm{N}, \mathrm{P}$ dan $\mathrm{K}$ dapat merangsang pembentukan anakan padi selain itu meningkatkan aktifitas fotosintesa sehingga diferensiasi sel akan lebih baik dan mengakibatkan jumlah anakan meningkat.
Jumlah anakan maksimum padi dengan pemberian asap cair cenderung mengalami peningkatan yang tidak signifikan disebabkan oleh waktu pemberian asap cair yang tidak efektif merangsang pembentukan anakan. Pada penelitian ini waktu pemberian asap cair dimulai pada pada umur 40 hari. Hal ini menyebabkan efek dari faktor tunggal asap cair tidak berpengaruh signifikan terhadap jumlah anakan. Jumlah anakan maksimum tertinggi yakni 47.33 batang dihasilkan pada kombinasi campuran biochar $(\mathrm{SP}+\mathrm{TK})$ diikuti dengan pemberian asap cair SP.

\section{Jumlah Anakan Produktif}

Tabel 3 menunjukkan jumlah anakan produktif meningkat secara nyata pada pemberian biochar SP, TK dan campuran biochar (SP+TK) masing-masing sebesar 8.23, 7.11 dan 11.34 batang, begitu juga pada pemberian asap cair SP dan TK meningkat secara nyata (7.42 dan 8.09 batang), sedangkan interaksi antara biochar campuran $(\mathrm{SP}+\mathrm{TK})$ diikuti dengan pemberian asap cair SP jumlah anakannya lebih banyak dibandingkan tanpa perlakuan (kontrol). Interaksi perlakuan ini menghasilkan jumlah anakan produktif terbanyak dibandingkan perlakuan lainnya.

Tabel 3. Jumlah Anakan Produktif (batang) Tanaman Padi yang diberi Biochar dan Asap Cair dari Sekam Padi dan Tempurung Kelapa.

\begin{tabular}{|c|c|c|c|c|}
\hline \multirow{2}{*}{$\begin{array}{l}\text { Jenis Biochar } \\
\left(\text { ton } \mathrm{ha}^{-1}\right)\end{array}$} & \multicolumn{3}{|c|}{ Asap Cair (\%) } & \multirow{2}{*}{ Rata-Raté } \\
\hline & Tanpa Asap Cair & $\operatorname{SP}(0,5)$ & $\operatorname{TK}(0,5)$ & \\
\hline Tanpa Biochar & 26.33 & 27.33 & 27.67 & 27.11 \\
\hline $\mathrm{SP}(10)$ & 32.00 & 34.33 & 37.33 & 34.56 \\
\hline TK (10) & 31.33 & 34.33 & 34.67 & 33.44 \\
\hline $\mathrm{SP}(5)+\mathrm{TK}(5)$ & 36.00 & 39.00 & 38.00 & 37.67 \\
\hline Rata-Rata & 31.42 & 33.75 & 34.42 & \\
\hline
\end{tabular}

Keterangan : Angka - angka yang diikuti oleh huruf kecil yang sama menunjukkan berbeda tidak nyata menurut uji lanjut $\mathrm{BN} J$ taraf 5\%. SP = Sekam Padi dan TK = Tempurung Kelapa .

Peningkatan jumlah anakan produktif sangat tergantung pada jumlah anakan maksimum pada fase vegetatif tanaman. Jumlah anakan produktif cenderung mengalami peningkatan pada pemberian biochar disebabkan karena retensi hara yang tinggi menyebabkan akar mampu menyerap unsur hara yang tersedia sehingga merangsang pembentukan jumlah anakan maksimum yang lebih banyak.

Biochar mampu meningkatkan ketersediaan hara bagi tanaman akibatnya memperlancar proses metabolisme dan fisiologi dalam tubuh tanaman sehingga meningkatkan pertumbuhan tanaman termasuk jumlah anakan maksimum dan produktif tanaman.

Jika diamati lebih detail jumlah anakan maksimum memiliki jumlah yang lebih tinggi dibandingkan jumlah anakan produktif. Menurut Soemartono et al. (1984) yang menyatakan bahwa jumlah anakan produktif mengalami pengurangan jika dibandingkan dengan jumlah anakan per rumpun disebabkan 
oleh adanya anakan yang mati dan anakan yang tidak produktif, hal itu dikarenakan persaingan sesamanya untuk mendapatkan unsur hara, cahaya dan air yang dibutuhkan.

\section{Umur Keluar Malai}

Tabel 4 menunjukkan bahwa umur keluar malai cenderung lebih cepat pada pemberian biochar SP, TK dan campuran biochar $(\mathrm{SP}+\mathrm{TK})$ sekitar 5-7 hari, begitu juga pada pemberian asap cair SP, bahkan pada asap cair TK mempercepat secara nyata umur keluar malai, sedangkan interaksi antara biochar SP dan asap cair TK lebih nyata mempercepat umur keluar malai yaitu pada umur 64.67 hari dibandingkan tanpa perlakuan (kontrol).

Tabel 4. Umur Keluar Malai (hari) Tanaman Padi yang diberi Biochar dan Asap Cair dari Sekam Padi dan Tempurung Kelapa.

\begin{tabular}{|c|c|c|c|}
\hline \multirow{2}{*}{$\begin{array}{c}\text { Jenis Biochar } \\
(\text { ton ha-1) }\end{array}$} & \multicolumn{3}{|c|}{ Asap Cair (\%) } \\
\hline & Tanpa Asap Cair & SP $(0,5)$ & $\operatorname{TK}(0,5)$ \\
\hline & & -----hari-- & ----- \\
\hline $\begin{array}{l}\text { I anpa Blochar } \\
\text { SP (10) }\end{array}$ & $\begin{array}{l}74.6 / \mathrm{a} \\
70.33 \mathrm{ab}\end{array}$ & $\begin{array}{l}70.33 \mathrm{ab} \\
67.67 \mathrm{ab}\end{array}$ & $\begin{array}{l}72.00 \mathrm{ab} \\
64.67 \mathrm{~b}\end{array}$ \\
\hline TK (10) & $70.67 \mathrm{ab}$ & $68.67 \mathrm{ab}$ & $68.00 \mathrm{ab}$ \\
\hline $\mathrm{SP}(5)+\mathrm{TK}(5)$ & $71.00 \mathrm{ab}$ & $69.00 a b$ & $69.00 \mathrm{ab}$ \\
\hline
\end{tabular}

Keterangan : Angka - angka yang diikuti oleh huruf kecil yang sama menunjukkan berbeda tidak nyata menurut uji lanjut BN $J$ taraf $5 \%$. SP $=$ Sekam Padi dan TK $=$ Tempurung Kelapa .

Pemberian asap cair dapat mempercepat umur keluar malai disebabkan kandungan asap cair dalam jumlah yang rendah $(0.5 \%)$ dapat merangsang pertumbuhan tanaman melalui proses fisiologi dan metabolisme tanaman. Sehingga mempercepat proses generatif tanaman. Hal lain yang menyebabkan yaitu asap cair hasil pirolisis (pyroligneous acid) disebut juga sebagai plant growth promotor atau senyawa perangsang pertumbuhan tanaman (Van Staden et al., 2006). Yatagai (2002) menyatakan bahwa komponem kimia asap cair seperti asam asetat berfungsi mempercepat pertumbuhan tanaman. Light et al. (2010) menyatakan bahwa pirolisis senyawa-senyawa organik seperti selulosa dan hemi selulosa mengandung perangsang pertumbuhan tanaman seperti senyawa karrikinolide (butenolide). Hasil penelitian di atas menunjukkan bahwa asap cair dapat mempercepat umur keluar malai.

Pemberian biochar ke dalam tanah meningkatkan dapat meningkatkan ketersediaan hara bagi tanaman melalui sifat fisik yang porous dan KTK nya yang tinggi mengakibatkan retensi hara retensi hara semakin meningkat dan akar tanaman cenderung mudah menyarap hara yang diperlukan pada proses fotosistesis untuk pembentukan jaringan daun dan anakan. Hasil fotosintat yang melimpah akan memacu pembentukan organ penyimpanan yaitu dengan mengeluarkan malai. Prihmantoro (2002) menyatakan bahwa unsur $P$ merupakan salah satu unsur yang sangat penting bagi pertumbuhan tanaman terutama pada bagian yang berhubungan dengan perkembangan generatif seperti pembungaan dan pembentukan biji.

\section{Bobot Kering Jerami}

Tabel 5 menunjukkan bahwa bobot kering jerami meningkat nyata pada pemberian biochar SP dan campuran biochar (SP+TK), begitu juga pada asap cair SP dan TK, namun biochar TK cenderung meningkat sedangkan interaksi antara campuran biochar (SP+TK) diikuti pemberian asap cair TK menghasilkan bobot kering jerami tertinggi dibandingkan perlakuan lainnya. Bobot kering jerami disajikan pada Tabel 5.

Tabel 5. Bobot Kering Jerami Padi (gram) yang diberi Biochar dan Asap Cair dari Sekam Padi dan Tempurung Kelapa.

\begin{tabular}{|c|c|c|c|c|}
\hline $\begin{array}{l}\text { Jenis Biochar } \\
\left.\text { (ton ha }^{-1}\right)\end{array}$ & Tanpa Asap Cair & $\begin{array}{c}\text { Asap Cair (\%) } \\
\text { SP }(0,5)\end{array}$ & $\operatorname{TK}(0,5)$ & Rata-Rata \\
\hline & & -1--orar & $\operatorname{sun}^{-1}-\cdots$ & \\
\hline Tanpa Biochar & 98.77 & 98.77 & 98.77 & 98.77 \\
\hline SP (10) & 119.91 & 119.91 & 119.91 & 119.91 \\
\hline TK (10) & 112.21 & 112.21 & 112.21 & 112.21 \\
\hline $\mathrm{SP}(5)+\mathrm{TK}(5)$ & 123.26 & 123.26 & 123.26 & 123.26 \\
\hline Rata-Rata & 110.98 & 110.98 & 110.98 & \\
\hline
\end{tabular}


Pemberian biochar SP, TK dan campuran keduanya meningkatkan bobot kering jerami sekitar 19-29\% dibandingkan tanpa pemberian biochar (kontrol). Peningkatan bobot kering jerami disebabkan oleh kandungan beberapa hara yang dimiliki oleh biochar seperti nitrogen C-organik, $\mathrm{P}, \mathrm{Ca}$, $\mathrm{Mg}, \mathrm{K}$ dan $\mathrm{Na}$ menjadi pensuplai hara bagi tanaman. Selain itu KTK biochar yang tinggi menyebabkan hara mudah diikat atau diretensi sehingga tidak mudah tercuci atau hilang pada bidang koloid tanah. Ketersediaan hara yang cukup di dalam tanah akan dimanfaatkan oleh tanaman melalui serapan akar tanaman. Keadaan tersebut mendorong proses metabolisme yang terjadi pada tubuh tanaman akan semakin meningkat, termasuk fotosintesis, mengakibatkan laju fotosintesis semakin tinggi dan semakin banyak fotosintat yang terbentuk. Semakin banyak fotosintat yang dihasilkan maka berat kering tanaman akan semakin tinggi juga. Widowati et al. (2012) menyatakan biochar selain mengandung beberapa unsur hara juga memiliki fungsi sebagai amandemen/ pembenah tanah dan mampu menahan hara dari pencucian (leaching) karena memiliki kapasitas tukar kation yang tinggi, sehingga hara yang dibutuhkan tanaman tetap tersedia dan dapat menghasilkan bobot kering biomasa tanaman lebih baik.
Pemberian asap cair meningkatkan bobot kering jerami sekitar 24.71 dan $26.23 \%$ dibandingkan tanpa asap cair (kontrol). Hal ini menunjukkan bahwa asap cair berperan dalam meningkatkan berat kering tanaman. Light et al. (2010) menyatakan bahwa pirolisis senyawa- senyawa organik seperti selulosa dan hemi selulosa mengandung perangsang pertumbuhan tanaman seperti senyawa karrikinolide (butenolide). Pemberian asap cair cenderung berperan sebagai perangsang pertumbuhan tanaman seperti tinggi tanaman pada Tabel 1. Akibat senyawa perangsang tersebut akan meningkatkan metabolisme dan serapan hara tanaman di dalam tanah. Akibatnya pertumbuhan dan perkembangan tanaman (biomassa) serta bobot kering tanaman ikut meningkat.

\section{Indeks Panen}

Tabel 6 menunjukkan indeks panen padi gogo pada pemberian biochar, asap cair ataupun interaksinya tidak menunjukkan hasil yang berbeda nyata. Hal ini disebabkan karena pada saat fase pembentukan malai hingga pada fase pengisian gabah, tanaman terserang penyakit blas yang disebabkan oleh jamur (Pyricularia oryzae Cav) dan hawar daun bakteri yang disebabkan oleh bakteri (Xanthomonas oryzae pv). Kondisi tanaman yang terserang dapat dilahat pada gambar 1.

Tabel 6. Indeks Panen Padi yang diberi Biochar dan Asap Cair dari Sekam Padi dan Tempurung Kelapa.

\begin{tabular}{lcccc}
\hline $\begin{array}{c}\text { Jenis Biochar } \\
\text { (ton ha } \text {-1 }^{-1} \text { ) }\end{array}$ & Tanpa Asap Cair & $\begin{array}{c}\text { Asap Cair (\%) } \\
\text { SP }(0,5)\end{array}$ & TK $(0,5)$ & Rata-Rata \\
\hline Tanpa Biochar & 0.10 & 0.08 & 0.12 & 0.10 \\
SP (10) & 0.12 & 0.11 & 0.10 & 0.11 \\
TK (10) & 0.10 & 0.09 & 0.10 & 0.10 \\
SP (5) + TK (5) & 0.05 & 0.11 & 0.10 & 0.09 \\
\hline Rata-Rata & 0.09 & 0.10 & 0.11 &
\end{tabular}

Keterangan : Angka - angka yang diikuti oleh huruf kecil yang sama menunjukkan berbeda tidak nyata menurut uji lanjut $\mathrm{BN} J$ taraf 5\%. SP = Sekam Padi dan TK = Tempurung Kelapa.

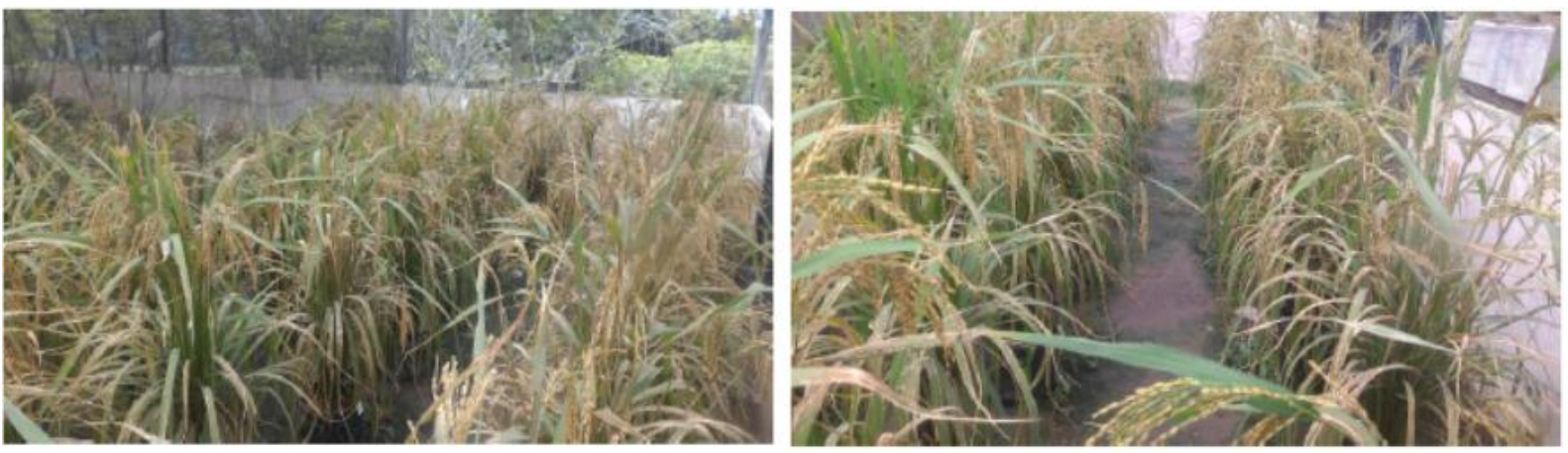

Gambar 1. Kondisi Tanaman yang Terserang Penyakit.

Indeks panen menggambarkan perbandingan antara bobot bahan kering hasil panen biologi dan hasil panen ekonomi dan sangat bergantung pada besarnya 
translokasi fotosintat. Semakin tinggi nilai indeks panen berarti semakin besar hasil biji yang dihasilkan. Pemberian pupuk hayati maupun pupuk hijau sampai dosis tertentu meningkatkan indeks panen karena dapat meningkatkan hasil ekonomi berupa bobot biji. Peningkatan hasil panen berupa biji terutama disebabkan oleh peningkatan indeks panen. Dengan kata lain, tanaman yang tidak lagi memproduksi bobot kering total, tetapi lebih banyak membagi bobot keringnya bobot keringnya ke hasil panen.

\section{KESIMPULAN DAN SARAN}

1. Pemberian biochar sekam padi, tempurung kelapa dan campuran keduanya (SP+TK) dapat meningkatkankan tinggi tanaman, jumlah anakan maksimum, jumlah anakan produktif dan bobot kering jerami.

2. Asap cair sekam padi dan tempurung kelapa dapat meningkatkan tinggi tanaman, umur keluar malai dan bobot kering jerami.

3. Interaksi antara biochar sekam padi, tempurung kelapa dan campuran keduanya $(\mathrm{SP}+\mathrm{TK})$ dan asap cair sekam padi dan tempurung kelapa meningkatkan tinggi tanaman dan umur keluar malai.

\section{DAFTAR PUSTAKA}

Chan, K.Y., van Zwieten, B.L., Meszaros, I., Downie, D. \& Joseph, S. 2007. Agronomic values of greenwaste biochars as a soil amandments. Australian Journal of Soil Research, $45: 625-634$.

Darmaji, P. 1996. Kadar benzopyren produk-produk asapan tradisional. Prosiding Seminar Nasional Makanan Tradisional. Hotel Jayakarta. Yogyakarta.

Departemen Pertanian. 2008. Pengelolaan Tanaman Terpadu (PTT) Padi Gogo. Departemen Pertanian. Jakarta.

Endriani., Sunarti, dan Ajidirman. 2013. Pemanfaatan Biochar Cangkang Kelapa Sawit sebagai Soil Amandement Ultisol Sungai BaharJambi. Jurnal Penelitian Universitas Jambi seri Sains, 15 (1) : 39-46
Gani, A. 2009. Biochar Penyelamat Lingkungan. Balai Besar Penelitian Tanaman Padi. Warta Penelitian dan Pengembangan Pertanian, 31 (6).

Glaser. 2002. Ameliorating Physical and Chemical Properties of Highly Weathered Soils in The Tropics With Charcoal: A review. Biol. Fertil. Soils. 35: 219-230.

Hardjowigeno, S. $2003 . \quad$ Ilmu Tanah. Akademi Persindo. Jakarta.

Jamilah. 2014. Pengaruh Dosis Urea dan Arang Aktif terhadap Sifat Kimia Tanah dan Pertumbuhan serta Hasil Padi Sawah (Oryza sativa L.). Sains Riset Volume, 4 (1).

Lehmann, J. 2007. Bioenergy In The Black, Frontiers in Ecology and the Environment.

Liang, B., Lehmann, J., Solomon, D., Kinyangi, J., Grossman, J., O'neill, B., and Neves, E. G. 2006. Black carbon increases cation exchange capacity in soils. Soil Science Society of America Journal, 70 (5) : 1719-1730.

Light, M.E., Burger, B.V., Staerk, D., Kohout, L., Van Staden J. 2010. Butenolides from plant derived smoke : Natural Plant-growth Regulator with antagonistic action on seed germination. Jurnal of Natural Products, 73: 267-269.

Muhakka., A. Napoleon., dan H. Isti'adah, 2013, Pengaruh Pemberian Asap Cair terhadap Pertumbuhan Rumput Raja. Pastura, 3 (1) : 30-34.

Prasetyo, B.H. dan D.A. Suriadikarta. 2006. Karakteristik, potensi, dan teknologi pengelolaan tanah ultisol untuk pengembangan pertanian lahan kering di Indonesia. J. Litbang Pertanian, 25(2) : 39-46.

Prihmantoro, H. 2002. Memupuk Tanaman Sayuran. Penebar Swadaya. Jakarta.

Saputra A.R.T., L. Rahmawati., D. Budianta., S.J. Priatna. 2016. Serapan Nitrogen pada Pertumbuhan Padi (Oryza Sativa L.) dengan Pemberian Biochar di Lahan Rawa Lebak. Prosiding Seminar Nasional Lahan Suboptimal 2016. Palembang. 
Subagyono, K., Haryati, U. dan Talaohu, S.H. 2004. Teknologi Konservasi Tanah pada lahan kering dalam Konservasi Tanah pada Lahan Kering Berlereng. Pusat Penelitian Tanah dan Pengembangan Tanah dan Agroklimat. Badan Litbang Pertanian. Departemen Pertanian.

Soemartono, B., Samad dan R. Hardjono. 1984. Bercocok Tanam Padi. Yasanguna. Jakarta.

Tsuzuki, E., Y. Wakiyama, H. Eto and H. Handa. 1989. Effect of pyroligneous acid and mixture of charcoal with pyroligneous acid on the growth and yield of rice plant. J.Crop Sci, 58 : 592-597.

Van Staden, J., Saprg, S. G., Kulkarni, M. G. and Light, M. E. 2006. Postgermination effects of the smokederived compound 3-methyl-2Hfuro[2,3-c]pyran-2-one, and its potential as a preconditioning agent. Field Crops Res, 98 : 98-105.

Widowati, W. H. Utomo, B. Guritno, L. A. Soehono. 2012. The Effect of Biochar on the Growth and N Fertilizer Requirement of Maize (Zea maysL.) in Green House Experiment. Journal of Agricultural Science, 4 (5) : 255-262.

Yatagai. 2002. Utilization of charcoal and wood vinegar in Japan. Graduate School of Agricultural and Life Sciences. The University of Tokyo. 


\section{J U R N A L AGROTEKNOLOGI Journal of Agrotechnology}

RESPON PERTUMBUHAN DAN HASIL TANAMAN SELEDRI TERHADAP NUTRISI DAN NAUNGAN MENGGUNAKAN SISTEM HIDROPONIK RAKIT APUNG

Growth and Production Response of Celery on nutrion and shading rate Using Floating Hydroponics System

Mercy Bientri Yunindanova, Linayanti Darsana dan Ardianto Pradana Putra

PERTUMBUHAN PADI GOGO PADA MEDIUM ULTISOL DENGAN APLIKASI BIOCHAR DAN ASAP CAIR

Application of Biochar dan Liquid Smoke to the Growth of Upland Rice (Oryza sativa. L) on Ultisol Medium

John Ivan Ndruru, Nelvia dan Adiwirman

PENGGUNAAN ATRAKTAN ASAM KLOROGENAT PADA PERANGKAP DALAM MENGENDALIKAN PBKo (Hypothenemus hampei Ferr.) PADA PERKEBUNAN KOPI DI KABUPATEN DAIRI

The Utilization of Chlorogenic Acid Attractant in Traps to Controlling PBKo (Hypothenemus hampei Ferr.) on Coffee Plantation in Dairi

M Mustain Aziz, Ameilia Zuliyanti Siregar dan Hasanuddin

SELEKSI BEBERAPA GENOTIPE PADI SAWAH LOKAL (Oryza sativa L.) TERHADAP CEKAMAN KEKERINGAN MENGGUNAKAN POLYETHYLENE GLYCOL (PEG) PADA FASE PERKECAMBAHAN

Selection of Many Genotypes the Rice Paddy Local (Oryza sativa L.) Against Drought Stress Using Polyethylene Glycol (PEG) in the Phase of Germination

Shinta Sawitri, Rabbana Saragih dan Ervina Ariyanti .....

ISOLASI BAKTERI Rhizobium DARI TUMBUHAN LEGUMINOSA YANG TUMBUH DI LAHAN BERGAMBUT

Isolation of Rhizobium From Legume That Growth In Peatland

R. Danang Suto Pamungkas dan M. Irfan

UJI PESTISIDA NABATI SIRIH HUTAN (Piper aduncum L.) TERHADAP LARVA KUMBANG TANDUK Oryctes rhinoceros L. PADA TANAMAN KELAPA SAWIT

Test of Piper Bettle Forest (Piper aduncum L.) Against The Larvae Horn Beetle Oryctes rhinoceros L. On Palm Oil Crop

Joni Irawan, Rusli Rustam dan Hafiz Fauzana. 